\title{
PREDISPOSING FACTORS ASSOCIATED WITH DISEASES IN ANIMALS IN NIGERIA AND POSSIBLE BOTANICAL IMMUNOSTIMULANTS AND IMMUNOMODULATORS: A REVIEW
}

\author{
K.T. Biobaku ${ }^{1}$ and S. A. Amid ${ }^{2}$ \\ ${ }^{1}$ Department of Veterinary Pharmacology and Toxicology, ${ }^{2}$ Department of Veterinary Radiology and Surgery, \\ University of Ilorin, Ilorin
}

\begin{abstract}
The factors predisposing to diseases in Nigeria, Sub-Saharan was classified basically as animal, environmental, cliental among others. This review was aimed at broadening the horizon of the Veterinarian. These factors were discussed in the light perspective of the peculiarity of Nigeria being a developing country. The write- up also proffered some solutions using organic botanicals agents which are relatively safe in food animals with little residual effect. Some of the plants suggested are: Allium sativm, Curcuma longa, Discorea japonica, Ziginber officinale, Jatropha gossipofolia, Datura spp and Boerhaavia diffusa. Supplements suggested are ascorbic acid, citric acid and Vitamin E. Immunomodulating supplements suggested are interferons, L-carnitine. The immunomodulating and immunostimulating agents suggested could be used in immunocompromised animals due to contemporary predisposing factors to diseases in this geographical region.
\end{abstract}

Keywords: Predisposing, factors, diseases, botanicals and immunomodulators

\section{INTRODUCTION}

Predisposition to diseases is a latent susceptibility to diseases which may be activated under certain conditions (Studdert et al., 2012).The predisposition to diseases could be classified to four basic factors which include: animal factor, environmental factor, client factor and sometimes veterinarian's factor.

Animal factors include the following; genetic and pedigree, peculiar genomic make-up, species, age, sex, allergy, status of the animal (lactation and gestation period), ability to physiologically adapt to certain external and internal stress, nutritional status and tumors (Scott, 2007; Biobaku and Shamaki, 2010; Mercks, 2010; Thiruvenkandan et al., 2011)

Environmental factors include; climatic and weather conditions; relative humidity, ambient temperature, sun intensity and wind speed. Geographical region, management system, disasters, insurgence, cattle rustling, vegetations and ecological factors, others environmental factors include environmental disposition to xenobiotics and desert encroachment (Garg, 2008; Okediran et al., 2010; Mercks, 2010)

This write up is a review aimed at explaining some important factors (the cliental factors, educational status, socio-economical factors, philosophy, habits, and bio-security measures) that predispose animals to diseases in Nigeria, Sub-Saharan Africa and stating some readily available supplements and plants of organic source. There are some substances in plants peculiar to this region that could elicit their potentials as immunostimulants and some immunomodulators which could be used in achieving better prognosis. The predisposing factors to animal diseases in developing countries change with contemporary challenges in these Sub-regions many of which have adverse impact on the gross domestic product value and to the veterinarian. It is believed that this write-up would broaden the horizon to the modern Tropical veterinarian and might aid policy makers in the livestock industry.

\section{METHODOLOGY}

Researches, case reports, text books, reports, dissertations, thesis and other commissioned research materials that add value to the subject area were used as sources of information for this review.

\footnotetext{
*Corresponding e-mail address: biobaku.kt@unilorin.edu.ng 


\section{ANIMAL FACTORS}

\section{Genetic factors}

Hereditary diseases are diseases that are developed mainly on hereditary basis or are inherited (Studdert et al., 2012). There are diseases predisposing factors due to genetic factors. There are some peculiar breeds that suffer some disorders more than some breeds of the same species (Wiles et al., 2017). Amongst the disorders most prevalent in the purebred German shepherd which is among the most bred in Nigeria could predisposed to lipoma, skin or cutaneous cyst and hypersensitivity (O’Neill et al., 2017; Wiles et al., 2017). In a very recent study the short haired Weimaraner breed of dogs. This breed is predisposed to progressive retinal atrophy (Kropatsch et al., 2017).This is a retinal disorder associated with gradual vision impairment due degeneration of retinal photo receptors of the eye Kropatsch et al. (2017). The molecular basis for this is the first four exons of the X-linked retinitis pigmentosa GTPase regulator (RPGR) is known to be involved in the progressive retinal atrophy (Kropatsch et al., 2017). Also in a previous study in dog breeds the purebred dogs are often stated to be predisposed to some diseases due to inbreeding pressure (Urfer et al., 2007).Dilated cardiomyopathy is a disease common in Doberman pinscher, Boxer, Great Dane, St. Bernard, Afghan hound and Cock Spaniel (Urfer et al., 2007). The clinical course of the diseases varies within breeds. Osteogenic sarcoma is common in Wolfhound after this breed of dog is the German Shepherd breed of dog. Other diseases in which the wolfhound is predisposed to is also the osteochondriosis and osteochondritis dissecans (Urfer et al., 2007). In a most recent study as of the time when this write-up is compiled. The German shepherd dog which one of the most common exotic breed of dog in this region and is one of the most patronized by dog breeders (Oboebgulem and Nwakonobi, 1989).A demographic study had shown the most frequent disorders in this breed are as follows. Otitis externa, osteoarthritis, diarrhoea, obesity and aggression and its most common cause of death is musculoskeletal disorders (Kropatsch et al., 2017). In poultry, there are genomic basis to the resistance of some diseases. Resistance refers to anti-disease ability or reduced susceptibility. General resistance, under the control of multigenes and influenced by environment. There is the display of defensive functions and immunity to most pathogens (Thiruvenkandan et al., 2011). In the case of resistance dominated gene, confers special resistance peculiar to some diseases and pathogens (Thiruvenkandan et al., 2011). The disease resistant genes are those encoding antibodies, microRNA and other material that help the host resist the damage caused by pathogens. MHC (Major histocompatibility complex) genes which confers resistance against coccidiosis by boosting the immune status of the animal, Nramp (Natural resistance-associated macrophage protein1) genes which encode specific proteins which restrain specific intracellular pathogens effectively (Thiruvenkandan et al., 2011). If mutation occurs in the NrampI gene leads to marked susceptibility to Salmonella pullorum (Thiruvenkandan et al., 2011). IFN (Interferon) genes are said to have antivirus ability, the IFN- $\alpha$ and IFN- $\beta$ possess this characteristics, IFN is also said to have antimicrobial effect. The interferon genes are resistant to infectious bronchitis virus, fowl pox and influenza virus (Thiruvenkandan et al., 2011). Mx (Myxovirus resistance) genes, which is the most studied gene family in chicken and is associated with resistance to avian influenza and infectious bursal disease virus (Thiruvenkandan et al., 2011). It is widely accepted that chicken Mx protein and Asn/ser at the $631^{\text {st }}$ amino acid could lead resistance or susceptibility to disease. $A L V$ (Avian leucosis virus) genes and Zyxin gene are also other genes of resistance in avian. So birds that don't have these unique genes would be more predisposed (Thiruvenkandan et al. 2011). These resistance genes features are peculiar to some breeds that are less predisposed to disease.

\section{SPECIES}

Animal species have diseases peculiar to them due to the fact that pathogens have preference to particular hosts. For example parvovirus infection in dogs, foot and mouth disease in bovine, Cowdria ruminatium in goats, African horse sickness in equine, swine fever porcine, Spring viraemia in fish. Some unique diseases are directly species specific but have wider species host target such as rabies. Rabies could infect all warm blooded animals but in spite this; it is still one of the top ten species specific that affect canine species (Merks, 2010).

\section{AGE}

The age of an animal could be a predisposing factor to diseases. Neonates have higher tendency to be infected than their adult. This is due to the fact their cell mediated immunity and humoral immunity is still developing. 
For this reason, it is advisable to the farmers and pet owners to ensure neonates take colostrums to enhance their immune status (Scott, 2007).Puppies are predisposed to parvoviral enteritis (Merks, 2010). Kids are predisposed to peste des petites ruminants, other diseases that affect the young are neonatal lamb disease, E. coli infection, and pneumonia due to bordetallosis because their immunity and thermoregulatory mechanism in young animals is not developed (Scott, 2007). Calves are predispose to rotavirus, coccidiosis and cryptosporidiosis (Merks, 2010). These diseases rarely affect the adult. In the same vein, old animals are also predisposed to tumors and other diseases.So old or young age predisposes them to diseases.

\title{
Sex of the animal
}

Storm abortion affects pregnant females and clinically gives a manifest form of the disease. Contagious agalactia, gangrenous mastitis, toxoplasmosis, campylobacteriosis in ewe and does (Scott, 2007). Female animals are also predisposed to mycotic abortion unlike in males. In this case, pregnant animals are liable to come down with mycotic abortion if predisposed to food contaminated with aflatoxins (Biobaku et al., 2016). Chlamydia and leptospira infections also affect female animals more than their male counterparts. Cystic ovary disease also manifest more in heifers, bitches, does, ewes and female cats (Merks, 2010).Some diseases also affect males and not the females an infection exemplified by this is Actinobacillus seminis infection in rams.Other diseases could affect both males and females. Examples include; genital horse pox, equine venereal balanitis in stallion caused by Equine herpes virus type 3 (EHV-3) (Oladosu, 1995). Ovine posthitis and vulvitis with a predisposing factor of high intake of protein coupled with Campylobacteria infection in male and female animals respectively (Scott, 2007).In males, it is manifested as the inflammation of the prepuce and glans penis (Scott, 2007). In the females it affects the vulva which is associated with swelling and bleeding. This disease is also associated with conditions of infection of Corynebacterium renale or other urease producing organisms such as Mycoplasma mycoides mycoides and Arcanobacteria pyogenes (Scott, 2007). In dogs, for example males Wolfhound are more predisposed to gastric dilation volvulus than the females (Urfer et al., 2007).

\begin{abstract}
Allergy
An individual animal might manifest anaphylactic reaction or type one hypersensitivity reaction. In cattle it can result to an atypical interstitial pneumonia. The main target organ is the lung for type hypersensitivity reaction. It had been documented that DL-tryptophan rich grasses could also predispose cattle to allergy and respiratory syndrome which is manifested as emphysema and bronchopneumonia (Bishop, 2005). Horses, cats and dogs might also have respiratory related allergies. This could predispose them to various secondary respiratory opportunistic diseases. The pathophysiological basis to this is in animals the respiratory tract is lined with pseudostratified columnar epithelial cells. Interspersed between the epithelial cells are goblet cells (Esievo, 2017).An allergen would trigger mast cells, eosinophils and other cellular components infiltration this would subsequently cause degranulation of the mast cell and the release vaso-active substance that would elicit bronchoconstriction these would stimulate the parasympathetic component of the autonomic system which is associated with increased mucous secretion coupled with brochoconstriction (Wanamarker and Massey, 2009; Sandhu, 2014) .Other immune related reactions would involve the pro-inflammatory cytokines which would result to inflammation of the respiratory tissues such as the lungs and the bronchi (Dhama et al., 2008). This would result to pneumonia and bronchopneumonia. This would predispose the animal to secondary opportunistic organisms to infect the respiratory system and could manifest as sneezing, coughing, wheezing, rhinitis, sinusitis and other signs.
\end{abstract}

\section{Animal behaviour}

An animal could be aggressive agonistic, anxious or could have abnormal behaviour of dominance (Merks, 2010). This could predispose them to confrontation in competition for scarce resources. This could also predispose them to injuries and if not detected could predispose to tetanus. They could be fearful animals and defeated psychologically and not have easy access to food. This could cause starvation immunocompromise and could predispose to diseases. A rear behaviour in Gallus domesticus at brooding, which two hens brood mutually could result to the two hens manifesting their maternal behaviour for days even though they hatch few or none. The remain dormant and isolate themselves for more than 21 days with very little time for feeding, sun and sand bathing .They manifest this behaviour under the influence of progesterone and endorphine (Biobaku and Adeleye, 2012). This coupled with physiologic changes at laying could predispose them to stress and diseases if 


\section{Biobaku and Amid}

not ameliorated. Animals could be adrenalized when confined as in cats and could either attack other animals, pet owners and might get themselves injures to get access to doors when enclosed in a confinement or when in a house all these could be detrimental to the health and wellbeing of the animal and could compromise the immunity due to high cortisol surge, which could predispose the animals to diseases (Ajadi et al., 2012) .This is because a number of neuroendocrine changes could be involved and this could have psychosomatic influence which would predispose to a distortion in the normal function and homeostasis of the animal's body.

\section{Nutritional status of the animal}

Animals that are well fed are less predisposed to diseases. This is because they have better immunity than animals that are malnourished Ameen et al. (2016). In Sub Saharan Africa where there are scarce resources, pets are either not well fed or are malnourished. These animals would be predisposed to arrays of diseases. Animals that are fed on balanced diets are resistant to diseases (Merks, 2010). In some experimental studies carried out in ruminants animals that are placed on good nutritional plane were able withstand trypanosome infection than animals malnourished. In another study animals that are placed on high energy diet including maize bran were able to live longer when challenged with trypanosome infection than animals not well feed Biobaku et al. (2008b). The dynamics of parasitaemia would change due to the immunity and endocrine system involved to favour the animal survivability (Biobaku and Shamaki, 2010). In Sokoto red goats allowed to feed extensively fed on lush and browse which enhanced their cell mediated immunity and increased the occurrence of erythrophagocytosis which is an adaptation against foreign organisms Tambuwal et al. (2002).Exogenous and natural, magnesium and zinc supplements with other sources of antioxidants reduced osmotic fragility in erythrocytes and stabilized their membranes which improved the survivability of animals in trypanosome endemic areas such as Sub Sahara (Biobaku et al., 2008a; Biobaku et al., 2008b; Biobaku and Shamaki, 2010). The use of leguminous plants in improvement of serum protein the albumin and globulin could decrease the tendency of negative protein balance which could be improve the immune system. Pakia biglobosa improved the plane of nutrition and brought about recovery in malnourished rats (Biobaku et al., 2017b). All the aforementioned gave some credence to the fact that good nutrition improves immunity and prevent diseases. Malnourished animals are more predisposed to diseases, because starvation predisposes to stress. Stress compromises both the inherent and adaptive immunity and could generate oxidative radicals that are detrimental for the homeostasis this invariably at the run compromises immunity (Jibir, 2008; Biobaku et al., 2016a). In the North eastern and north western zones of Nigeria at rains many farmers embark on subsistence agriculture Hassan, (2000). This leaves livestock owners no option but to keep animals in confinements. Most peasant livestock owners hardly afford maintaining their animals for long. This compromises nutrition, their immunity and predisposes them to diseases Hassan, (2000).

\section{Tumors}

Animals with tumors are predisposed to immunocompromise and are predisposed to secondary infections (Merk, 2010). This depends on the type location and the tumor. An insulinoma could cause changes in metabolism (Sandhu, 2014). This could predispose to hypoglycemia and could change blood glucose level. This would affect the health status of the animal and could cause immunocompromise. Wanamarker and Massey, (2009).The chronic nature of the tumor could also lead to a progression of disease. Tumor cells could interact with the cell mediated and immoral immunity. Hence, tumors could predispose to other form of diseases (Merk, 2010). From the clinical perspective also, the treatment of animals using antineoplastic drugs which are cytotoxic could cause immunosupression. These predispose the animals to super infections and secondary bacterial, protozoal and fungal infections. Malignant tumors when they undergo metastases to the neighboring tissues such as lymphoid organs such as lymph nodes, spleen, tonsils, mesenteric lymph nodes, and thymus. This could spread faster unlike benign tumors and this would further compromise the immunity of the animals which would predispose to diseases. So, in the management of tumors, clinicians should administer supportive drugs aimed at mitigating the detrimental effect of antineoplastic drugs (Temitope et al., 2010; Biobaku et al., 2011). Such supportive drugs are antioxidants such as Vitamin C, Vitamin A, Vitamin E, selenium and some natural nutriceutical agents such as Parkia biglobosa, Vernonia amagdalina, and noni Juice, Omega fatty acids, Allium sativum supplements among others Awoyomi et al., 2013; Biobaku et al., 2017c). 


\section{Physiological adaptation to internal and external stress}

Animals that are subjected to internal stress such as pains due to endogenous production of cyclooxygenases, prostaglandins, thromboxane prostacyclins, substance P, serotonine, dopamine, kallikrein, bradykinin and other factors generated endogenously (Sandhu, 2014). These bring about alarm reaction if the stress factor those not persist for a long time (Biobaku et al., 2016b; Biobaku et al., 2017a).The neuroendocrine mechanism will triggers adjustment of the physiological distortion. The faster the body could adjust to homeostasis mechanisms to counteract the physiological upset, the less the predisposition to disease (Biobaku et al., 2017b).This is because glucocorticoids from the cortex of the adrenal medulla will produce cortisol endogenously. This affects the leucocytes count which will eventually decrease the cell mediated immunity. This might cause fulmination of the disease causing agent and will cause a spread of the disease from organ to organ. In some animals, cortisol could be produced as endogenously or (exogenously) xenobiotics (Garg, 2008). This might lead to secondary bacterial infection due to immunocompromise. There are also scientific basis that cortisol surge in an organism could cause joint induce corticosteroid pains (Merk, 2010). In some cases, if the stress is prolonged, this would cause the body to adjust itself by the general adaptive syndrome. This requires more time, caloric involvement and other biochemical changes. This is a syndrome and could predispose to diseases. In production animals, it could affect products like beef, chevon, hides and skin (Biobaku et al., 2016a; Singh, 2007).

\section{ENVIRONMENTAL FACTORS}

Relative Humidity: High humidity at wet season and the disposition of animal housing such as in poultry farms buildings on areas that are not levels could cause accumulation of water in ditches especially when water tables to the surface. Damp litters due to high moisture and poorly constructed pens could predispose to coccidiosis (Hall, 1985; Urquhart et al., 2003). Similarly, in a wet and humid environment of the tropical rain forest in Nigeria could also predispose rabbit to pneumonia and could cause snuffles due Pasteurella spp and other pathogenic organisms that could cause upper respiratory diseases. During the wet season, the incidence of dermatophylosis in cattle and horses tend to increase. Ectoparasites such as ticks, flees, flies, thrive better in high humid damp environment (Urquhart et al., 2003). In the same vein, vector diseases that are transmitted by these parasites are on the increase in animals. The incidence of helmenthosis in high humidity also increases in ruminants, pigs and equines (Urquhart et al., 2003). Glossina spp of river areas transmit diseases in tropical rain forest (Urquhart et al., 2003).Therefore, animals are predisposed to trypanosomosis which is influenced by high humidity. Dermatophylus congolense occurrence increases in the wet season especially in tropical Sub-Saharan Africa (Shaibu and Adetosoye, 2008). In the dry season, the incidence of fungal skin infestation, scabies and other skin diseases decrease. Nature had made it that at high humidity, the ruminants thrive better due to good grazing because of fresh herbage that is fed upon by the animals. This tends to improve the immunity of the animals due to the flavonoids and other antioxidants present in the grasses. It had been documented in literature that animals that are extensively managed to feed on browse plants. Such animals are goats, sheep, antelope and buffalos in the wet season and at high humidity feed on selected plant that could be of medicinal value. Some of these plants include; Khaya senegalensis, Annona senegalensis, Adansonia digitata, Tridax procumbens, Aspillia africana, Carica papaya,Acacia albida, Acacia nilotica, Balanitis aegyptica and goat weed are among plant fed in a free range to confer immunity to the animals naturally from helminthes (Urquhart et al., 2003; Sanni et al., 2005; Akinyemi et al., 2005; Awoyomi et al., 2013). In the dry season, at low humidity grazing of animals becomes more difficult and access to fresh herbage would be difficult and this could compromise the immunity. The natural trees for browse wilt to adapt for high transpiration in the semiarid zone of the Savannah. These animals at adverse lower humidity would find it difficult to feed, this condition causes compromise in the immunity.

\section{Ambient temperature}

Temperature as it is known is the degree of hotness and coldness of a particular region. In Tropical SubSaharan Africa, temperature could rise high at hot dry season to a few degrees Celsius in the harmattan (Ismaila.et al., 2010). At high temperature and with poor nutrition predisposes animals to stress and diseases. In Northern Nigeria, Gallus domesticus extensively reared suffer high incidence of New castle disease and mortalities due to stress (Agaie and Uko, 1998). Other diseases transmitted are chronic respiratory disease, coryza, salmonellosis and infectious laryngotracheitis amongst others (Agaie and Uko, 1998). Prior to the wet 


\section{Biobaku and Amid}

season, at the wet and harmattan seasons, animals could be predisposed to respiratory infections, the lambs, kids and calves due to their undeveloped thermoregulatory are predispose to some respiratory syndromes and peste des petites ruminants (Scott, 2007). Nasal enzootic adenocarcinoma in a West African doe was reported, initially the case manifested as a respiratory syndrome, but diagnosed to be nasal enzootic adenocarcinoma (Ajayi et al., 2013). It might not be too far to correlate the climatic changes amongst factors that contribute to manifestation of oncogenic factors coupled with an incriminating pathogenic which is of class D retrovirus (Ajayi et al., 2013). Pigeons are predisposed to New Castle disease and pigeon pox at harmattan (Hall, 1985; Agaie and Uko, 1998). Pigeon pox which is caused by a pox virus which could cause blindness and form lesions that could obstruct the oral cavity and oropharynx of birds which could eventually lead to death. Although, these are self limiting diseases in this species at the harmattan season in North Western Nigeria (Hall, 1985; Agaie and Uko, 1998). High ambient temperature or extreme low temperature of the harmattan could affect aquatic life and fish such as the Clarias spp could be dormant in early hours of the day and later feed in warmer hours. These affect the feed conversion ratio and could predispose to stress and diseases (Ezeri, 2014).

\section{Geographical region}

The geographical region where the animals are bred also could be one of the environmental factors that could contribute to predisposition of diseases (Urquhart et al., 2003). Animals bred in such area could be exposed to some diseases peculiar to the region. In Nigeria, Sub Saharan Africa and South of the equator the trypanosomosis belt spreads along latitude $4^{\circ} \mathrm{N}$ to $13^{\circ}$ (Onyiah, 1997). Animals that are not trypanotolerant are predisposed to trypanosomosis infection. There are various strains of trypanosomes and other haemoparasitic infections. The trypanosome breed is more resistant to this endemic parasite in Nigeria.(Onyiah, 1997).The breeds of cattle that are trypanotolerant include; the Keteku, muturu and the Ndama breeds and are more resistant than the Bororo, Gudali and white fulani breeds. The West African Dwarf goat is more resistant than the Sahel, Sokoto red and Maiduguri brown (Ameen et al., 2016). These resistant breeds of animals were found to have higher magnesium concentration in their plasma than other less resistant breeds. These resistant animals thrive better in the Tropical Rain Forest better than the predisposed counterparts. The pathogenic progression of the disease might not favour survival of animals not adapted to this geographical zone. An example of this is a German shepherd dog bought from South Africa had episodes of epilepsy due to the encephalitic form of Trypanosome congolense (Biobaku et al., 2015). This animal was predisposed to the infection due to region factor and the progression of the disease was faster which resulted to the trypanosomes sequel to meningitis to reach blood brain barrier and cause distortion in the polysynaptic mid brain and changed the dynamics of neurotransmitter (Biobaku et al., 2015).Which caused the episodes convulsion. This could occur in other exotic dogs the progression of the disease takes time. Another example of the geographical factor predisposing animals to disease is a case of a Friesian breed of bull important and brought to the North western region of Nigeria. Less than three months after purchase it was predisposed to bovine babesiosis (Urquhart et al., 2003). This is because this geographical zone has this diseases endemic because of the vectors of these disease (Urquhart et al., 2003).The disease progression and course of the disease was very protracted, after which the animal manifested classical signs of babesiosis which was jaundice, haemoglobinuria, anaemia weight loss and anorexia (Urquhart et al., 2003). This exotic bull in this geographical zone lacked pre-immunity or enzootic stability. Exotic animals when introduced into this a particular region different from where they were purchased should be offered intensive care with regular prophylaxis for some time until they develop pre-immunity and acclimatize to the new environment. Papillomatosis in cattle caused by papilloma viruses had been reported in Nigeria as a transboundary disease (Zwandor et al., 2008). This means if animals are introduced in these regions they should be routinely vaccinated regularly and offered prophylactic therapy to enable time develop immunity over time. In North central zone of Nigeria the collaborative scheme between two business parties embarked on a diary breed cattle New Jersey for breeding and milk production (Biobaku, 2015).The management of the animals became relatively difficult and there were losses due trypanosomosis, aflatoxicosis, babesiosis, dermatophylosis and bovine contagious pleuropneumonia among others. These diseases are basically among the contending factors in the management of these exotic animals bought from outside Nigeria. The indigenous animals and the cross bred animals in this zones thrived better in this geographical zone using the same management systems than the pure bred exotic breed. So the geographical zone with its contending endemic diseases predisposes animals to diseases. Clinicians must ensure appropriate veterinary care, biosecurity and quarantine measures when animals are introduced to a new geographical zone. 


\section{Management system}

Management systems also affect the immunity of animals and could predispose to diseases if compromise. Intensively managed animals are less predisposed to diseases. This is because they are routinely vaccinated and prophylactically treated overtime. They are therefore, less predisposed to dangers and stress conditions. In the South western part of Nigeria, if animals are extensively managed and while grazing they could be predisposed to injuries. Some hunters set traps in bushes. The grazing animals might be injured by the traps and animals might go unnoticed by herdsmen. In literature, a case reports of Aeromonas hydrophila which was difficult to diagnose and treat in bovine, which affected the health of the animal (Awoyomi et al., 2014) Many animals moved by transhumance and nomads might have their immunity overwhelmed and could eventually die. Poultry managed intensively are predisposed to cage stress if such birds are not properly managed could be predisposed to diseases (Hall, 1985).

In recent time animal welfare agencies frowned against keeping birds battery cages and prefer the deep litter system. In the same vein, birds kept intensively might be predisposed to disease occurrence because of the tendency that diseases could spread faster in cages. The stocking of the animals also is another factor if animals are over populated predisposes them to coccidiosis and other respiratory diseases (Hall, 1985). Management system is also another factor that affects disposition pertaining to health. Animals in captivity are predisposed to diseases, if previously managed extensively and kept to run on in a free range and suddenly changed to be managed intensively, this would predispose the locally bred animals to diseases if they are poorly nourished and exposed to stress of restraint. It had been documented in literature that animals bred in Sub-Sahara had significant changes in their haematological parameters when managed semi-intensively or intensively, even when fed on balanced rations. Animals managed extensively feeding in free range and on browse had significantly higher PCV and leukocytes count. The differential leucocytes parameters also showed better cell mediated immunity than animals managed intensively. It means that the extensive system is better for the local breed of animals (Sonibare et al., 2007).

Transportation of animals during for breeding or slaughter if not done using stipulated standards could predispose the animals to diseases. In Nigeria research work carried out in transportation of food animals at long and short terms affected the animal's haemogram. The animals also had increased neutrophils-lymphocytes ratio which is evident of stress (Ayo et al., 2006; Biobaku et al., 2016). The cell mediated immunity was lowered and humoral this could predispose animals to diseases. There would be high cortisol surge that could be detrimental to the health of the animals (Ajadi et al., 2012). Stocking rate and transportation welfare if not properly rendered would predispose the animals to infections (Biobaku et al., 2017c). In the same vein, transportation stress could also affect the health which is detrimental to production (Biobaku et al., 2016). Animals when transported using inappropriate or irrational stocking predispose animals to immune-compromise, injuries and death. It is not uncommon to see dead animals along the high ways this cause losses incurred by people in the livestock industry (Singh, 2007; Biobaku et al., 2017a; Biobaku et al., 2017b). The meat from dead animals subjected to stress is not whole some and it is not only detrimental to man but also to other animals. In a study carried out in dogs, experimental animals were fed on animals exposed much stress and a significant number of experimental animals suffered stress meat syndrome (Irwin et al., 2012). This is also detrimental to reproductive health and general wellbeing of animals. The scientific basis to this is interaction of endogenously secreted cytokines and steroids from the animals subjected to stress in the consumer animal and man (Biobaku, 2015).

\section{Natural disaster, insurgence and cattle rustling}

Nigeria had environmental challenges including floods, bush fires, draught and rebellious insurgences among which predispose animal's to stress and diseases (Junaidu, 2016). Over flow of water bodies due to global warming and climatic change (Institute for Economic and Peace Development, 2015; Junaidu, 2016). Mismanagement of dams and domestic drainages cause over flow of water bodies at the wet season. Flood could affect sheep, goats and cattle and could predispose to stress, immunocompromise and diseases. Water lodged in clay and loamy soil could predispose bovine to foot rot which is cause by fusobacterium necrophorum, while in ovine it is caused by Dichelobacter nodosus and occurs only under very wet condition favours the proliferation of the bacteria in the soil (Scott, 2007). In ovine and caprine this is very infectious in the wet season and they suffer inflammation of the laminae of the hoof. Many animals are also predisposed to respiratory diseases most especially the lambs, kids and calves (Scott, 2007). 


\section{Biobaku and Amid}

The insurgences in Nigeria had left many animal breeders in a confused state (Junaidu, 2016). Many animals might get lost in the forest and might be left to so many stress factors including envenomation, Intoxication and starvation; because are left for days without objective grazing by a herdmen who are also contending with many life threatening factors (Junaidu, 2016). In the South east the animals are predisposed to heavy metal toxicity and oil spillage. In recent study lead predispose to intoxication to many animals and man in these environmentally polluted areas. This affects the metabolism and causes neurotoxicity. Younger animals and children are more predisposed to this form of disease predisposing factor (Okediran et al., 2010).

Between 2014 to 2016 about 202,017 cattle were reported rustled and over 1000 herdsmen and farmers were reported killed in Northwestern States of Nigeria; Kaduna, Kano, Katsina, Kebbi and Zamfara States (Junaidu, 2016). Livestock rearing is popular in the Northwestern States and traditionally farmers buy livestock with excess earning from annual harvest as savings also many farmers also have work oxen (De Haan,1994; Blench 2003). Cattle rustlers have on many occasion invaded these communities stealing cattle, impoverishing these rural dwellers and creating problems and controversies between farmers (Junaidu, 2016). Rustling has reduced the take-off of the nation, while insurgency had caused distortion in the cattle trade along the Northeastern corridor from the neighboring countries (Junaidu, 2016). This certainly would affect the movements of the cattle and since herdsmen embark solely on the extensive system and grazing animals on natural vegetation this change in dynamics would affect the feeding patterns of the animals and could predispose to diseases. These cattle settlements are threatened and need to wait for days to ensure safety in their routes of transhumance travel; which would affect the immune status of the animals and could predispose to disease.

\section{Environmental disposition to xenobiotics}

Nigeria is a country with diverse vegetative zones and animals interact directly or indirectly with the environment (Abatan, 2012). The vegetative and non vegetative part of the ecosystem posses various sources of xenobiotics (NRC, 2001). Some biological and non biologic sources include phytotoxins, zootoxins, mycotoxins and marine toxins (Garg, 2008; Biobaku et al., 2016b). Non biologic sources include edaphic exposure to xenobiotics such as in extraction companies, refineries, drug companies, mining firms, insecticides production. Access to heavy metal toxicity also compromises the immunity of the animals (ATSDR, 2005; Al-Forkan et al. 2016). Animals that are exposed to xenobiotics are therefore exposed to diseases than animals that are not. Xenobiotics exposure at prenatal period exposure may result to susceptibility to infectious diseases, allergic reaction or autoimmune disease (Sandhu, 2014). Many target chemicals cause immune suppression Chemicals clearly disrupt cell proliferation and clonal expansion (ATSDR, 2005; Al-Forkan et al., 2016). There could be disruption of T- cell maturation in thymus this mechanism for immunosuppression. Exogenous chemicals may also interfere with receptor ligands binding at the cell surface (Sandhu, 2014). Type I hypersensitivity reaction. (sometimes referred to as atopy) is mediated by antigen-specific cytophilic (Sandhu, 2014). Type I is also called immediate-type hypersensitivity Immediate asthmatic responses to allergen, allergic rhinitis (hay fever), atopic dermatitis (eczema), and acute urticaria (hives) (Sandhu,2014; ATSDR, 2005). Type II hypersensitivity result of antibody-mediated cytotoxicity that occurs when antibodies respond to cell surface antigens. Autoimmune diseases can result from drug treatments with penicillin, quinidine, quinine, or acetaminophen (Sandhu, 2014). Antigen-antibody (IgG) complexes that accumulate in tissues or the circulation, activate macrophages and the complement system, and trigger the influx of granulocytes and lymphocytes (inflammation) (Eseivo, 2017). This is also referred to as the Arthurs reaction and includes post-infection squealer such as rheumatic heart diseases (Sandhu, 2014).

\section{Vegetations and ecological factors}

Nigeria is endowed with different vegetative and ecological zones (Junaidu, 2016). Animals in different zones directly interact with their environment these include ruminants, equine, birds and wildlife. The animals that are managed extensively feed on grasses and other fauna from the ecosystem (Junaidu, 1999). This source of food and drinking water might have optimal or lower or higher than adequate minerals in herbage, grasses or pasture (Junaidu, 2016). There could also be varying nutritional and anti-nutritional factors that could be detrimental or useful to the health of the animals as the case might be. In soils where trace elements are deficient this could predispose the grazing animals to mineral or trace elements deficiency (Scott, 2007). An example is hypomagnesaemia, iron deficiency anaemia, copper deficiency, iodine deficiency among others. However, care 
must be taken when supplementation in feed or as salt licks in ovine because they are predisposed to copper toxicity (Scott, 2007; Mercks, 2010). For this reason serum chemistry and appropriate test should be conducted prior to supplementation. In the same vein, animals that are over exposed to some trace elements above their optimal required levels could also affect toxicities and metabolic diseases.

The edaphic factors (soil factors) such as $\mathrm{pH}$, alkalinity, salinity, profile, and structure,topography of farms and vegetation steepness or scantiness could also the health the animals and prevent or predispose animals to one or more diseases. In recent times for example snail and aquaculture had began to grow as a livestock enterprise in Nigeria (Ezeri, 2014). This factor affects this industry in a critical way. The soil type for example sandy soil, does not retain water, loamy possess relatively average water retention tendency. While the clay soil retains more water which would cause water lodging and eventually favors more parasites, bacterial, fungal proliferation these in warm Tropical zones could predispose to diseases (Biobaku et al., 2010; Ameen et al., 2015). The intensity of the sunshine and wind speed coupled with the absence or presence of moisture could predispose to diseases depending on the management system and species of the animal. High moisture and high water retention could be beneficial to good health of Clarias spp and other aquaculture breed species but might be challenging to Northern breed of goats such as the Sahel and other animals (Ezeri, 2014; Biobaku et al., 2016a). All these factors if not controlled by appropriate management systems could predispose to diseases.

\section{Desert Encroachment}

Environmental changes and draught affects vegetation in the Tropical Sub Saharan region (GIZ, 2015). The dryness of the wind accompanied with its high speed tends to increase in the harmattan season (GIZ, 2015). This causes the sand dunes of the Sahara to move towards its Southern region and towards the equator. These movement increases the Sahara land mass which had affected adversely the Savannah zones of Nigeria. In spite all efforts of Nigerian government in planting of trees as wind breakers (FMA, 2016). The Sahara still poses a challenge to Nigerian vegetation that has the highest population of cattle, sheep, goats and camels (FMA, 2016).This results to drying of the shrubs, grasses and other browse plants. Animals are commonly managed extensively and ruminants feed on grasses in the natural environment year-in and year-out (FMA, 2016; Junaidu, 2016). Draught could affect the vegetation cover and animals depend solely on the grasses in the wild (Junaidu, 2016). In the semi arid zone of Nigeria environmental changes is accompanied by draught would result to animals roaming for a considerable distance before getting sufficient grasses to graze (Junaidu, 2016). This would affect the nutritional status of the animals and would predispose the animals to stress and malnutrition (Biobaku et al., 2017c) Sequel to these conditions these would predispose the animals to various diseases condition. Apart from predisposing the animals to infectious diseases the likelihood of the grazing animals to feed on polythene bags and other materials might predispose them to rumen tympany, rumen atony, rumen stasis and bloat (Scott, 2007; Mercks, 2010). The incidence animals having high load of foreign materials could predispose them to metabolic disorders which would also predisposed to immune-compromise and disease conditions. This is because the immunity of such animals would be compromised in adversity of desert encroachment.

\section{CLIENT FACTORS}

The enlightenment of the client would aid good management of the animals (Junaidu, 2016). Good enlightenment and the level of education of the client would assist maintenance of good health. This means appropriate livestock practices in conformity with international standards would enhance good nutrition this would boost the immunity and health. In clients that are not enlightened this would not ensure good practices and this would affect immunity and hence predispose the animals to diseases. In the same vein, veterinary extension services and routine veterinary services which include health monitoring, routine; vaccination, deforming, supplementation of animals feed would be easily carried in enlightened client (Aliu, 2016). Compliance to prescription and routine vaccination schedules could be easily done in well enlightened clients unlike the unenlightened clients that misuse drugs and could predispose their animals to different conditions (Biobaku et al., 2016c; Aliu, 2016).

The social strata the client belongs to could also affect the health status of their animal (Babalobi, 2016).Clients in the high strata of the society embark on high standards animal practices unlike those in the lower strata this would affect the management procedures in their farms and feeding. Those that cannot afford good animal health practices might have their animals more predisposed to diseases (Junaidu, 2016). Access to good 
capital in livestock industry improves the health of the animals unlike those that are disadvantaged this would affect management and health (Aina, 2012). In Nigeria most goats keepers in the north are peasants and can only embark on the extensive systems at rain when animals are disallowed from being in the free range because of cultivation of farms this could compromise the health of the animals and predispose such animals to diseases (Aina, 2012). Farms that are well built also prevent the animals to be less predisposed to envenomation by snakes which could also compromise the animal's immunity and predispose to other diseases.

Security and biosecurity of the farms is an important factor that could predispose animals in a particular confinement to diseases (Junaidu, 2016). This because if the farms are properly secured would prevent stray animals and unrestricted humans from getting access into the vicinity where animals are bred (Junaidu, 1999). This depends on security measures such as fence, security personnel, alarms, automatic cameras and gates, guard dogs, electrical wire device and others. The more the farm is easily accessible without restriction the more the animals kept in such farm would be more predisposed to both endemic and transboundry diseases (Junaidu, 2016). This means that animal owners or clients that cannot afford such measures would have their animals more predisposed to diseases; while clients that have farmes that less security and biosecurity conscious might have their animals more exposed to the risk of contracting contagious diseases.

An experience of over a decade of veterinary practice had shown that habits of the client or owners are also among the factors that predispose to diseases. Some client is fond of giving their pets such as dogs and cats alcohol and chocolates (Aliu, 2007; Garg, 2008). This predisposes the animals to liver diseases and chocolate intoxication in pets this had been previously documented in literature. Clients also that are well to do over feed their animals with vitamin rich diets this could predispose their pets to hypervitaminosis and lameness due to metabolic causes (Booth and Mcdonald, 2008).

\section{THERAPEUTIC IMMUNOSTIMULATION AND IMMUNOMODULATION BY POSSIBLE BOTANICALS, SUPPLEMENTS AND INTERFERONS IN ANIMALS}

The aforementioned predisposing factors to diseases in Sub-Saharan region could be minimized or mitigated using some botanicals and supplements that are consumer safe from residue and exogenous agents that are detrimental to the health and wellbeing of the public. This requires the knowledge of pharmacology and immunology (Quinn, 1990: Singh et al., 2016)

Immunostimulation and modulation is prophylactic or therapeutic concept aimed at stimulation of the non specific immune system (Aliu, 2007). This means stimulation of the non antigenic dependent immunity thus causing the increased function and defense efficiency of the granulocytes, macrophages, complement and natural killer cells. It also could also involve the modulation of an increased immune reaction such as allergy or a depressed immune system as in immune compromise. (Aliu, 2007; Sandhu, 2014). Plant extracts that constitutes anethol, capiscum oleoresin, carvacrol, cinnamaldehyde, eugenol, oleoresin from Curcuma longa and Allium sativum conferred immunity in pigs (Liu, 2011). These extracts are said to increase cell viability of porcine alveolar macrophage, lipopolysaccharide and stimulation of IL-1 $\beta$ secretion. Previous studies had shown the Capiscum spp, Curcuma longa and Allium sativum improved immunity against E.coli and decreased the frequency of diarrhoea in pigs (Liu, 2011).Plants that were investigated to possess immunostimulating potential in fish are Viscum album, Urtica dioica, Zinginber officinale (Aranha et al., 2012; Singh et al., 2016).Extracts from these plants were discovered to increase phagocytic capability of rainbow trout and carp. Datura metel extract was used to boost immunity and reduced significantly mortality of ornamental fish in microbial infection (Pandey et al., 2010). In ruminants it was observed that animals that were placed on natural supplements rich in $\beta$-carotene, vitamin E, copper, zinc (such as in maize and maize bran) and selenium. Improved the cell mediated and humoral immunity (Biobaku and Shamaki, 2010; Scott, 2008). In rodents, Ocimum sanctum at 100mg/kg orally administered showed significant phagocytic index and boosted immunity. Jatropha gossipofolia considered to be safer than J.carcus. $L$ methanolic extract at $(0.25 \mathrm{mg} / \mathrm{kg}$ body weight $)$ in one-day-old specific pathogen free chicks was determined due to the plants immunostimulation tendency (Singh et al., 2016). Allium sativum possessed effect on mitogenicity and hypersensitivity cells. There was synthesis of protein associated with the administration of Allium sativum. The mitogenicity towards lymphocytes of murine splenocytes and thymocytes which is evident of its immunostimulating property. Boerhaavia diffusa at $40 \mathrm{mg} / \mathrm{kg}$ body weight elevated the levels of proinflammatory cytokines, TNF- $\alpha$, IL-1 $\beta$ and IL- 6 in mice this result gave credence to its immunostimulating potential (Manu and Kuttan, 2009). Dioscorea japonica with active principles 
Dj-dioscorins and TN1- dioscorins induce expression of proinflammatory cytokines and stimulates the phagocytosis of the bone, spleen and thymus. Dj-dioscorins enhances proliferation of CD4 (+) and CD8 (+), Th1cells in spleen and CD19 (+) in both spleen and thymus (Lin et al., 2009).Acacia Catechu produced a significant increase in phagocytic index and a significant protection against cyclophophamide induced neutropenia (Ismail and Asad, 2009). In frugivorous birds flavonoids improved the humoral immunity and was investigated to be due to its antioxidative potentials (Catoni et al., 2008).

\section{SUPPLEMENTS}

Vitamin E significantly increased sephadex-elicited inflammatory exudates and the percentage of phagocytic macrophage in broiler chicks injected in ovo (Khan et al., 2012). Percentage of macrophage and abdominal exudates cells were increased by administration of $200 \mathrm{mg} / \mathrm{kg}$ (Khan et al., 2012). The efficiency of phagocytosis by macrophages is increased by administration of supplemental vitamin $\mathrm{E}$ and phagocytosis is a membrane mediated phenomenon (Khan et al., 2012). Vitamin E elevated percentage CD4:CD8 at seven week of age. CD4 $(+)$ is the key player as a helper cells in antibody production. A level of $87 \mathrm{mg} / \mathrm{kg}$ of vitamin E increased the percentage of T helper cells CD4+CD8- in the thymus and spleen in the seventh week in broilers. Ascorbic acid is a common vitamin supplement most readily available that could be used in improvement of immune responses in most livestock (Khan et al., 2012). It possesses an antioxidative property and aids the cell mediated and humoral immunity. Its immunomodulatory effect had been previously documented in avians, pigs, sheep, goats, fish and wild life. It has an advantage that it has minimal residual effect and possess wider therapeutic window (Sandhu, 2014).

Citric Acid (CA) when supplemented in broiler feed showed high density immunocompetent cells in the gastrointestinal tract which is an indicator of healthy broiler with high immune status and protection against pathogens and infectious diseases (Islam, 2012) Higher globulin levels were found in broiler fed supplemented with CA diets (Islam, 2012). This shows better ability to resist diseases in the broilers (Islam, 2012). This also reflected on the ability to resist New castle Disease since recent study had shown that serum globulin level increase due to CA supplementation which could be evidence of resistance to the disease (Islam, 2012).

\section{USE OF HOST IMMUNE MODULATORS}

\section{L-Carnitine}

Carnitine in poultry takes part in the transfer of long chain fatty acids which modifies the metabolism of fatty acid enhances secretion of hormones such as insulin, insulin-like factor-1 and triiodothyronine which may be involved with several lipids and hormones to confer its immunomodulatory effect (Aliu, 2007; Adabi et al., 2011). L-Carnitine supplementation in pigeons increased Ig G and Ig A. At 100mg/kg supplementation in broiler chicken it modulated the innate immunity by enhancing the acute phase protein response (Aliu, 2007; Adabi et al., 2011). In addition L- carnitine supplementation also helps as an antioxidant by regulating nitric oxide, cellular respiration, increase in the anti-oxidative enzymes such glutathione peroxidase, catalase, superoxide dismutase (Aliu, 2007; Adabi et al., 2011; Sandhu, 2014). It exerts thiol and methionine sparing capacity all these decrease the predisposing to stress and improves its immunomodulatory effect (Aliu, 2007; Adabi et al., 2011; Sandhu, 2014).

\section{Interferons}

Interferons are family of glycoproteins produced endogenously by mammals in response to a viral infection or viral infected cells secret this to enhance their binding to receptor on the cell membranes of other uninfected cells, thus this confers antiviral effect to other cells and makes them inaccessible to other pathogens (Aliu, 2007;Dhama 2008;Studdert et al.2012; Sandhu,2014).Now interferon is produced by recombinant DNA technology in bacteria with aid of genes from human leukocytes (Sandhu, 2014). There are at least three types, classified previously according to their antigenic property and physical properties. Recently classified as class I which includes $\alpha, W$ and $\beta$. While the class II are the interferon; IFN- $\alpha$ (leukocyte interferon type 1 ); IFN- $\beta$ (fibroblast interferon type 1); IFN-r (immune interferon, type II) which constitutes a family of hormones involved in modulation of immune reactions (Dhama, 2008; Studdert et al., 2012; Sandhu, 2014). They are produced by $\mathrm{T}$ and natural killer cells $(\mathrm{NK})$. The interferon-gamma are termed as immune interferon which 


\section{Biobaku and Amid}

produced mainly in by T-lymphocytes as part of the immune response to both viral and non-viral antigens which include bacteria and their product, rickettsiae, protozoa, fungal polysaccharides and a range of polymeric chemicals and other cytokines (Dhama, 2008; Studdert et al., 2012; Sandhu, 2014). IFN- $\alpha$ and IFN- $\beta$ are produced by $\mathrm{B}$ and $\mathrm{T}$ lymphocytes, macrophages and fibroblasts in response to the presence of viruses and cytokines. The mechanism of action of interferons is it causes the synthesis of host cell enzymes such as protein kinase, 2', 5'-oligoadenylate synthetase, and phosphodiesterase which inhibit RNA translation and leads to the degradation of viral mRNA and tRNA. It also has antiproliferative and possibly antineoplastic activities may be due to its effect on the synthesis of RNA, DNA and cellular proteins oncogenes (Aliu, 2007). Interferon also acts by stimulation of the immune system (Dhama 2008; Studdert et al., 2012; Sandhu, 2014). The therapeutic uses of interferon as IFN- $\alpha$ had been proven useful in the treatment of infectious bovine rhinotracheitis virus (Aliu, 2007). Given orally to treat non-neoplastic feline leucopenia virus. IFN- $\alpha$ is approved in the treatment of certain cancers such as hairy cell leukaemia, Kaposi sarcoma, or condylomata acuminate caused by papilloma virus, herpes simplex viral infections (Aliu, 2007). Intranasal administration of interferons could be prophylactically used to prevent rhinoviral cold but not useful in already infected subjects (Aliu, 2007). Interferons had been combined with antiviral drugs such as acyclovir or vidarabine and were proven to have promising effect in the management of chronic hepatitis B and C infections (Aliu, 2007; Dhama, 2008; Studdert et al., 2012; Sandhu, 2014. An intralesional injection of interferon in genital warts was used in the speeding up of its regression (Aliu, 2007). INF-r in combination with pentavalent arsenicals was successful in the management of leishmaniasis (Aliu, 2007). Dosage and treatment regimes; IFN 30 IU rhIFN- $\alpha$ orally administered in cats SID for $1 / 52$; IFN is given intravenously at a dose of $10^{6}-10^{9}$ units daily except in cats it is not effective orally, and causes adverse effects limits its IM or SC injection (Aliu, 2007).

\section{CONCLUSION AND RECOMMENDATION}

There are many factors predisposing to diseases in different species in Nigeria, but this write-up gave a review for the basic understanding of the most pertinent causes. It is important to bear in mind that despite the fact that Nigeria and West Africa Sub-region is endowed with flora that could be exploited in complementing the modern veterinary medicine. It is important to know that good management practices, hygiene, breeding nutrition and biosecurity still remain the most economic and effective way to prevent diseases in Nigeria. There is scarcity of effective veterinary drugs and immune based agents among which is interferon, while other supplements are still in preclinical trials in veterinary practice in this region.

Enlightenment to stakeholders in the livestock industry should be increased. Veterinary extension workers and agricultural extension workers should be trained to bridge the gap between clients of different strata of social system for ensuring good animal health and profit. Good policy to ensure security in farms. This should be done using multidisciplinary approach to ensure effectiveness of a profitable livestock sector. Research should be encouraged to ensure proffering solution with peculiar reference to the region which ever changing and challenging.

\section{REFERENCES}

1. Abatan MO (2012) Poisons and poisoning nightmarish of a society without diagnostic tools: an inaugural lecture. Ibadan University Printery 18-27.

2. Adabi SHG, Cooper RG, Ceylan N and Corduk M (2011). L-Carnitine and its functional effects in Poultry Nutrition, World Poultry Science Journal 67:277-296.

3. Agaie BM and Chafe UM (1998). Prevalance of gastrointestinal parasites in small ruminants in Sokoto, Sokoto State of Nigeria. The Beam 4:123 -128.

3. Agaie BM and Uko OJ (1998). Effect of season, sex and species difference on the packed cell volume of guinea and domestic fowls in Sokoto, Sokoto State of Nigeraia. Nigerian Veterinary Journal 19:95-99.

4. Aina ABJ (2012).Goat a misunderstood animal, 35TH Inaugural lecture presented at Federal University of Agriculture, Abeokuta, Nigeria.

5. Ajadi RA, Kehinde OO, Sonibare AO, Gazal OS and Kasali OB (2012). Effects of road transportation of cattle between transboundry area and central abattoir of Abeokuta, Ogun State on Plasma cortisol, blood glucose and leukocyte parameters. Bulletin of Animal health production 60:373-376.

6. Ajayi OL, Oyewusi IK, Olaniyi MO, Oyekunle MA, Jagun AT, Omotainse SO, Biobaku KT and Kasali OB (2013). Enzootic nasal adenocarcinoma: cytological and clinico-pathological observations: In a West African dwarf goat. A Case report. Bulletin of Animal Health and Production in Africa. 61:331-335. 
Predisposing factors associated with diseases in animals

7. Akinola LAF and Essien A (2011).Relevance of rural poultry production in developing countries with special reference to Africa. World's Poultry Science Journal 67:697-705

8. Akinyemi KO, Mendie UE, Smith ST, Oyefolu AO and Coker AO (2005). Screening of some medicinal plants used in South-west Nigerian traditional medicine for anti-Salmonella typhi activity. Journal of Herb Pharmacotherapy 5: 45-60.

9. Al-Forkan M, Islam S, Akter R, Shameen AS,Khaleda L, Rahman Z and Salma CDU (2016). A sub-chronic exposure study of arsenic on haematological parameters, liver enzyme activities, histological studies and accumulation pattern of arsenic in organs of Wistar albino rats Al-Forkan, Journal of Cytolology Histolology (pages 1-7) Available from: S5:1http://dx.doi.org/10.4172/2157-7099.S5-006 accessed $15^{\text {th }}$ August,2016.

10. AliuYO (2007).Veterinary pharmacology 1st Edition published by Tamaza publishing, Zaria, Nigeria.447-488.

11. Aranha I, Clement F and Venkatesh YP (2012). Immunostimulatory properties of the major protein from the stem of the Ayurvedic medicinal herb, guduchi (Tinospora cord folia).Journal of Ethnopharmacology 139:366-72.

12. ATSDR (Agency for Toxic Substances and Disease Registry) (2005). Toxicological Profile for Arsenic (update)., Atlanta, Georgia, pp. 1-357.

13. Awoyomi OJ, Biobaku KT, Kehinde OO, Adebowale OO and Oyewusi, JA (2013). A Survey of ethnoveterinary botanicals in Ogun State and their public health Implications. Nigerian journal of Animal Production 40: 198-208.

14. Awoyomi OJ, Oyewusi JA, Talabi AO, Oyewusi IK, Biobaku KT, Mustapha OA and Agbaje M (2014). Isolation of Aeromonas hydrophila in a Case of wound Infection in Cattle in Nigeria. Nigerian journal of Animal Production 41:213-219.

15. Ayo JO, Minka NS and Mamman M (2006). Excitability scores of goats administered ascorbic acid and transported during hot-dry conditions. Journal of Veterinary sciences 7:127-131.

16. Biobaku K T, Thomas FC, Aremu A, Asogwa NT, Ameen SA, Akorede GJ and Basiru A (2017c). Nutriceutical effects of fermented Parkia biglobosa seeds on recovery of malnourished rats. Ceylon Journal of Science 46:4753.

17. Biobaku KT (2015). Effect of xylazine and Ascorbic acid Co-administration on Transportation Stress and Meat Characteristics in Sahel bucks. A Ph.D Thesis Submitted to Department of Veterinary Phermacology,Usmanu Danfodiyo University, Sokoto.

18. Biobaku KT and Shamaki BU (2010). A preliminary Trypanocidal Study of Natural and Synthetic supplementation of Zinc and Magnesium in combination with Diminazene aceturate in wistar rats. Sahel Journal of Veterinary Sciences 9:55-61.

19. Biobaku KT, Agaie BM and Aremu A (2017b). Evaluating stress amelioration of oral vitamin C in bucks exposed to long term road transportation and stocking. Bangladesh Journal of Veterinary Medicine 15:33-38.

20. Biobaku KT, Agaie BM, Onifade KI, Odetokun IA, Okediran BS, Ameen SA, Ismaila MS, Adamu M and Raji LO (2016a). Effects of xylazine on physiological and biochemical parameters of sahel bucks exposed to long term road transportation of 28 hours. Sokoto Journal of Veterinary Sciences 14:43-52.

21. Biobaku KT, Ajagbonna OP, Ajayi OL and Adebowale OO (2008a). Efficacy of Magnesium chloride Supplementation and diminazene aceturate in Trypanosome brucei inoculated Wistar albino rats. Journal of Agricultural Science and Environment B 7:64 -70.

22. Biobaku KT, Ajayi OL, Ajagbonna OP and Omotainse SO (2008b). Effect of magnesium chloride and diminazene aceturate on the pathogenicity of Trypanosome brucei infection in rats. VOM Journal of Veterinary Science 1:47-53.

23. Biobaku KT, Jibir M, Agaie BM and Onifade KI (2017a). How xylazine Administration and adherence to Animal welfare Improved chevon of bucks exposed to road stress. Annals food Science and Technology 18:307-315.

24. Biobaku KT, Odetokun IA, Akorede GJ and Ameen SA (2015). A case of canine Trypanosoma congolense diagnosed by PCR and managed using diamiazene aceturte co administration with vitamin B and C. Sahel Journal of Veterinary Sciences 14:77-80.

25. Biobaku KT, Odetokun IA, Raji LO, Olurode SO, Ameen SA (2016b). A case report of abortion induced by Aspergillus mycotoxicosis in Sokoto Red goat. Alexandria Journal of Veterinary Sciences 49:91-94.

26. Biobaku KT, Raji LO, Akorede GJ,Odetokun IA, Ameen,SA (2016c). A Case of dystocia induced by misuse of oxytocin in a Boerboel bitch.Turkish Journal of Agriculture Food Science and Technology 4:822-824.

27. Biobaku KT, Takeet M I, Olurode SA, Oyewusi IK, Oni OO and Oloye AA (2010). The prevalence and clinicohaematological changes of protozoan disease in food animals in Alabata, Abeokuta. Nigerian Journal of Parasitology 31:1-6.

28. Biobaku KT, Thomas FC, Adenubi OT and Ajadi RA (2011). Effect of Tahitian noni juice on hematological and biochemical parameters. Tropical Veterinarian Journal 29:24-30.

29. Biobaku KT and Adeleye OE (2010). Two hens mutually brooding: A rare behaviour in Gallus domesticus ; A case report. Science World Journal 5:21-22. 


\section{Biobaku and Amid}

30. Bishop Y (2005). In: The Veterinary Formulary Publish in Association with Veterinary Association.6 edition Pharmaceutical press. London 100-125.

31. Butchers GD, Jacob JP and Mather FP (2015). Poultry Diseases. Document is PS47, one of a series of the Veterinary Medicine-Large Animal Clinical Sciences Department, UF/IFAS Extension, sourced from http://edis.ifas.ufl.edu.

32. Catoni C, Schaefer, HM and Peters A (2008). Fruit for health: the effect of flavonoids on humoral immune response and food selection in a frugivorous bird. Functional Ecology 22: 649-654.

33. Clement F, Pramod SN and Venkatesh YP, (2010). Identity of the immunomodulatory proteins from garlic (Allium sativum) with the major garlic lectins or agglutinins. International Immunopharmacology 10:316-24.

34. De- Haan C(1994). An Overview of the World Bank Involvement in Pastoralist Development. applications in veterinary practice. A review Journal Immunology and Immunopathology 10:79-89.

36. Esievo KAN (2017). Veterinary Clinical Pharmacology. First edition Spectrum books Limited.Nigeria. 85-165.

37. Ezeri GN (2014). Fish Diseases A Major Hinderance for 'Fish for all'. $44^{\text {th }}$ anugural Lecture. Published by Federal University of Agriculture Abeokuta, Nigeria pp 34-40.

38. Garg SK (2008). Veterinary Toxicology. CBS publishers and Distributors New Delhi-110002

39. GIZ (Deutsche Gesellschaft fur Internationale Zusammenarbeit) (2015).Joint Environmental Audit on the Drying up of Lake Chad Report.

40. Gregory GN (2004). Physiology and behavior of animal suffering. First edition Blackwell Publishing Company, United Kingdom. 25-50.

41. Hall HT (1985). Diseases and parasites of livestock in the tropics. $2^{\text {nd }}$ edition.Academic press. Pp. 207-241.

42. Hassan WA (2000). Biological productivity of sheep and goats under agro-silvo-pastoral system in the zamfara reserve in North-western Nigeria. Ph.D Thesis. Submitted to Department of Animal Science , Justus Liebig University, Giessen, Germany, 262 pp.

43. Institute of Economics and Peace (2015). Global Terrorism-Index-Report:In Junaidu,M (2016).The challenges of pastoralism on national economy security in compiled by veterinary council of Nigeria. Published by Veterinary Council of Nigeria, Nigeria. Islam KMS (2012). Use of Citric acid in broilers, World Poultry Science Journal 68:104-118.

44. Irwin, H.P., Cho, B.H and Oh, J.V (2012) Animal stress result in Meat causing diseases downloaded web version courtesy of Jean chemours website.

45. Ismail S and Asad M (2009). Immunomodulatory activity of Acacia catechu. Indian Journal Physiology and Pharmacology 53:25-33.

46. Ismaila MS, Onifade KI, Agaie BM, Elsa AT and Chafe UM (2010). The Influence of Environmental Temperature on Physiological Parameters in xylazine sedated Sheep. International Journal of Animal and Veterinary Advances 2:37-42.

47. Jibir M (2008). Effect of age, sex fasting on carcass and meat characteristics. A Ph.D Thesis Submitted to Department of Animal Science, Usmanu Danfodiyo University, Sokoto.

48. Junaidu M (1999). Management of common property resources for suitable Livestock production in Nigeria. DFID Workshop on Land Tenure, property and sustainable development in Sub-Saharan Africa presented at UK

49. Junaidu M (2016). The challenges of Pastoralism on National economy Security in Compiled by Veterinary Council of Nigeria. Published by Veterinary Council of Nigeria, Nigeria.

50. Khan RU, Naz S, Javdani M, Nikousefat Z, Selvaggi M, Tufarelli V and Laudadio V (2012). The use of Tumeric (Curcurma longa) in Poultry feed. World Poultry Science Journal 68:97-103

51. Khan RU, Rahman ZU, Nikousefat Z, Javdani M, Tufarelli V, Dario C, Selvaggi M and Laudadio V (2012) .Immunomodulatory effect of vitamin E in broilers. World Poultry Science Journal 68:31-39

52. Kropatsch1 R, Akkad1 DA, Frank M, Altmüller CRJ, Jörg PN, Epplen T. and Dekomien G (2016). A large deletion in RPGR causes XLPRA in Weimaraner dogs. Canine Genetics and Epidemiology 3:1-9.

53. Lin PL, Lin KW, Weng CF and Lin KC (2009). Yam storage protein dioscorins from Dioscorea alata and Dioscorea japonica exhibit distinct immunomodulatory activities in mice. Journal of Agriculture of Food Chemistry 57: 4606-13.

54. Liu Y (2011). Effects of plant extracts on immune function and disease resistance in pigs.PhD Dissertation Submitted to Graduate College of Animal Sciences, University of Illinois at Urbana-Champaign.

55. Lunne JK (1998). Cytokines orchestrating the immune response. Review of Science Technology Official international Journal Epizootology 17:84-94.

56. Makare N, Bodhankar S and Rangari V (2001). Immunomodulatory activity of alcoholic extract of Mangifera indica L. in mice Journal of Ethnopharmacology 78:133-137. 
57. Manu KA and Kuttan G (2009). Immunomodulatory activities of punarnavine, an alkaloid from Boerhaavia diffusa. Immunopharmacology and Immunotoxicology 31:377-87.

58. Mercks (2010). Mercks Veterinary Manual.10 ${ }^{\text {th }}$ Edition Mercks and Co. 2410-2540.

59. NRC (National Research Council, National Academy) (2001). Arsenic in the Drinking Water (update). Washington, DC: pp. 1-225.

60. O’Neill DG, Coulson NR, David BC and Brodbelt DC (2017). Demography and disorders of German 59. Shepherd Dogs under primary veterinary care in the UK. Canine Genetics and Epidemiology 4:1-12.

61. Oboebgulem SI and Nwakonobi LE (1989). Population density and ecology of dogs in Nigeria a pilot Study. Review Scientifique at Technique- officer. International Epizootics 8:733-745.

62. Okediran BS, Thomas FC, Ajibola ES, Biobaku KT, Olaniyi MO and Adeleye OE (2010). Effects of vitamin C on lipid profile of lead exposed. Occupational Workers Proceeding: 47th Annual Congress of the Nigerian Veterinary Medical Association, (NVMA).63-66.

63. Onyiah JA (1997). African animal trypanosomosis: An Overview of the current status in Nigeria. Tropical Veterinarian 15:111-116.

64. Pandey G, Sharma M and Mandloi AK (2010). Medicinal plants useful in fish diseases. Plant Archives 12:1-4.

65. Quinn PJ (1990). "Mechanism of action of some immunomodulators used in veterinary medicine". In : Advances in Veterinary Science and Comparative Medicine 38:44-67, Academic Press, USA.

66. Roger B (2001). A report on Pastoralists in the New Millennium: In Junaidu M (2016). The challenges of Pastoralism on National economy Security in Compiled by Veterinary Council of Nigeria. Published by Veterinary Council of Nigeria, Nigeria.

67. Roger B (2003). A report on Pastoralists in the New Millennium: In Junaidu, M (2016). The challenges of Pastoralism on National economy Security in Compiled by Veterinary Council of Nigeria. Published by Veterinary Council of Nigeria, Nigeria.

68. Sandhu HS (2014). Essentials of Veterinary Pharmacology and Therapeutics $2^{\text {nd }}$ edition, Kalyanani, New Delhi, India. 280-282.

69. Sanni FS, Ibrahim S, Esievo KA and Sanni S (2005). Effect of Oral Administration of Aqueous Extract of Khaya senegalensis Stem Bark on Phenylhydrazine-induced Anaemia in Rats. Pakistan Journal of Biological Sciences 8: 255-258.

70. Scott PR (2007). Sheep Medicine Manson Publishing Veterinary Press United Kingdom, 200-300

71. Shuibu SJ and Adetosoye EA (2008).Comparison of crude protein profiles of isolates of Dermatophilus congolense from cattle by SDS-Page Vom Journal of Veterinary Science 5:1

72. Singh N, Tailang M and Mehta SC (2016). A Review on herbal plants as immunomodulators. International Journal of Pharmaceutical Sciences and Research 7:3602-3610.

73. Singh V (2007). Universal meat hygiene in public health care published by international book distributing company New Delhi, India and Co pp 114-125.

74. Sonibare AO, Kumshe HA, Talabi AO and Biobaku KT (2007). Effect of sex and age on the haematology of West African dwarf (Fouta djallon) under three management system in Ibadan, Nigeria. Proceeding: 44th Annual.

75. Studdert VP, Gay CC and Blood DC (2012). Saunders Comprehensive Veterinary Dictionary 4th edition. Elsevier Saunders, United States of America.

76. Tambuwal FM, Agaie BM and Bangana A (2002). Haematological and Biochemical values of apparently healthy Red Sokoto goats. Proceedings of $27^{\text {th }}$ Annual Conference of the Nigerian society of Nigerian society of Animal Production, Federal University Technology, Akure, Nigeria: 50-53.

77. Temitope AA, Adenubi OT, Thomas FC, Khaleed TB, Effiong UA and Adetola AA (2011). Protective effect of Tahitian Noni Juice on the reproductive functions of male Wistar rats treated with Cyclophosphamide. Iranian Journal of Pharmacology and Therapeutics 10:39-43.

78. Thiruvenkandan AK, Prabakaran R and Panneerselvam S (2011). Broilers breeding strategies over decades: An Overview. World Poultry Science Journal 67:309-336.

79. Urfer SR, Gaillard C and Steiger A (2007). Lifespan and disease predispositions in the Irish wolfhound. A review Veterinary Quarterly 29:102-111.

80. Urquhart GM, Armour J, Duncan JL, Dunn AM and Jennings FW (2003).Veterinary Parasitological. $2^{\text {nd }}$ Edition. PP $276-277$.

81. Wanamaker BP and Massey KL (2009). Applied pharmacology for Veterinary Technicians Saunder Publications, Canada, pp 76-96.

82. Wiles BM, Llewellyn-Zaidi AM, Evans KM, O’Neill DG and Lewis TW (2017). Large-scale survey to estimate the prevalence of disorders for 192 Kennel Club registered breeds.Canine Genetics and Epidemiology 4:1-18.

83. Zwandor NJ,Akalusi SS,Meseko CA,Akanbi BO, Adedeji JA and Fagbamila LO (2008). Severe cutaneous bovine papillomatosis in cattle herd. Vom Journal of Veterinary Science 5:1. 